DOI: $10.19195 / 2084-5065.49 .5$

\title{
The development of the Roman alphabet and its implications for handwriting comparison in the British/Irish sphere
}

\author{
BRIAN CRAYTHORNE \\ ORCID: 0000-0002-7142-8843
}

Forensic Science Northern Ireland, UK

Much is known about the development of the alphabet but of course the earliest details are lost in the mists of time. The strongest theory is that Semitic peoples in contact with the ancient Egyptians borrowed the idea of writing from them along with some of their letter designs. In a stroke of genius they turned the very complicated system of hieroglyphics (which used a combination of logograms, syllabic and alphabetic designs which could only be written by the very educated) into a very simple alphabetic system which employed only a few characters. These few characters could be used to represent every possible word and could be readily learned by many people.

From the earliest Semitic alphabets the Phoenician alphabet was born. The Phoenicians were in contact with the ancient Greeks, who borrowed the alphabet from them. The Greeks adapted the alphabet for themselves and also took on board the Phoenician names of the letters but made them more Greek-sounding. One set of Greeks moved west to Italy and took the alphabet with them and passed it onto the Etruscans, who in turn passed it onto the Romans, who adapted it into the form we know today - with a few changes being made in the post-Roman period. As such the letters we use are called Roman or Latin letters. In the 
Dark Ages Christian scribes preserved writing and developed a lower case style known as uncial, which speeded up writing by simplifying the letters down to single strokes, often losing loops and extending serifs, and this was the basis of modern lower case letters.

Taking particular examples to illustrate the development of the Roman alphabet from its early beginnings I will use the letters A and B.

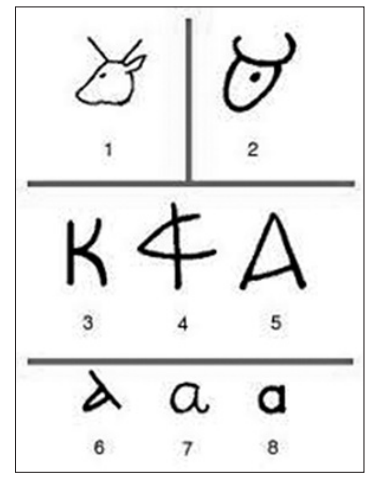

(1)

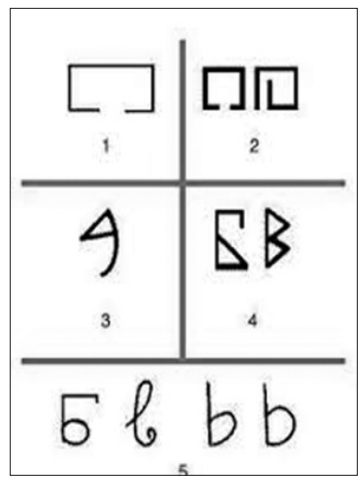

Figure 1. The development of the A (1) and B (2) through time, starting from the ox head and house shapes respectively

Source: www.britannica.com.

Early logograms representing words were pictures of objects and these then developed into signs representing the sound of the first letter. We still teach reading like this today when we say "A" is for "apple" and "B" is for "ball". The Egyptians had a sign which was a "reed shelter" but also represented the sound " $\mathrm{H}$ " in its alphabetic use. The early Semites used this symbol which looked like a house and named it "house" which is "beth" or "bayt" in the Northwest Semitic languages - a word which can still be seen in Biblical and modern day place names such as "Bethlehem" and "Bethel". Now the shapes of these 4000-year-old letter designs are still present in our designs today. Considering the letter $\mathrm{A}$, if we go back to $1750 \mathrm{BC}$ we find the letter $\mathrm{A}$ as an ox head, representing the sound of a glottal stop which was the beginning sound of the Semitic word for ox, which is aleph. 


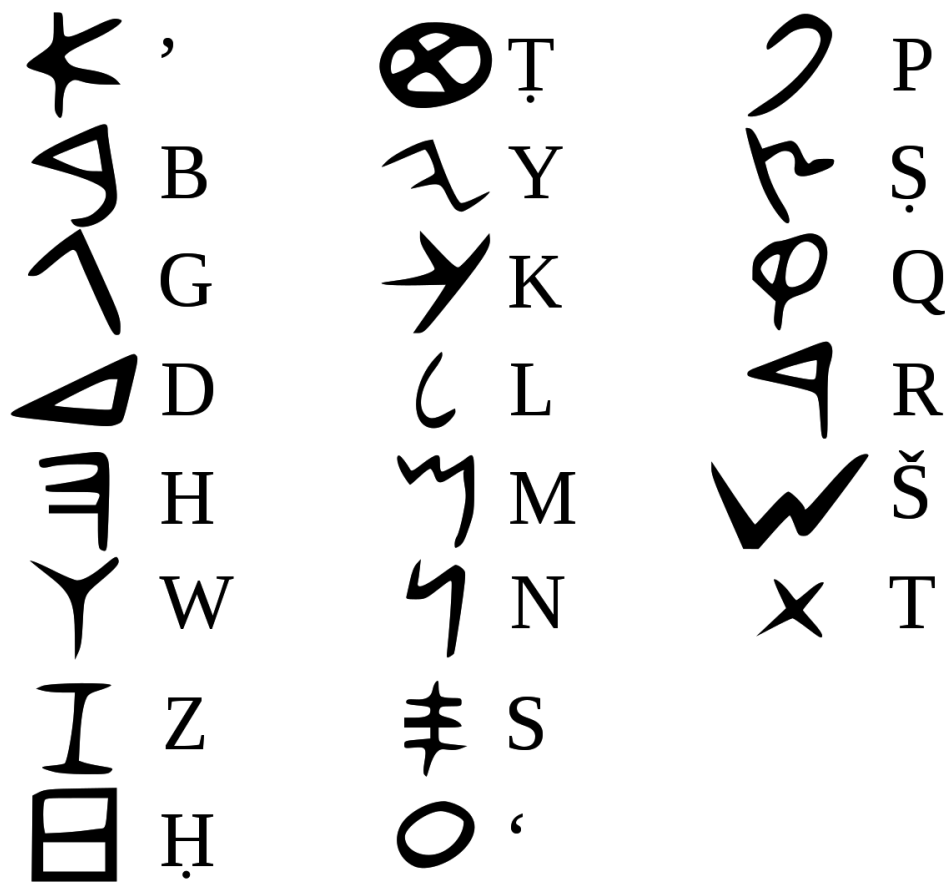

Figure 2. The Phoenician alphabet with the names of the letters and their modern equivalents

Source: www.wikipedia.com.

When the letters A and B entered the Phoenician alphabet the designs were developed and became slanted onto their sides. The Phoenicians passed the letters to the Greeks who altered them again and gave them names. Aleph became alpha and beth became beta. The letters also changed the direction they were facing. The Semitic languages were written right to left, as still done by Hebrew and Arabic, but when the alphabet was adopted by the Greeks after a period of experimentation the Greeks settled on writing left to right, which changed many of the Phoenician characters in orientation.

The Greeks kept the letters in the same alphabetical order and for most letters kept the same sound - such as the B, to which they added another loop to its shape. But the Greeks spoke an Indo-European language which needed to illustrate vowel sounds in written words much more so 
than the very different Semitic language of the Phoenicians. The clever Greeks took a letter representing a sound they did not have - the consonantal glottal stop - and used it as a vowel for the 'ah' sound. The Greeks also turned the A character upside down.

As the alphabet passed from the Greeks to the Etruscans and then to the Romans, the letters A and B now looked very much like our modern letters. Beautiful examples of the letters A and B and most of our other letters can be seen on Trajan's Column in Rome. All the time the letters remained fixed in the alphabetic positions numbers 1 and 2, where they were in the Phoenician alphabet. After the fall of the Roman Empire handwriting was kept alive by Christian scribes who by AD 500 were speeding up their writing turning the $\mathrm{A}$ into a lambda $\lambda$ shape (which later became "a") and by omitting the upper loop of the B to create a lower case letter "b" in the semi-uncial style. Scribal writing further developed into Carolingian miniscule and in the early 1400s in Italy humanist writings combined Roman capitals and Carolingian miniscule lower case letters to produce beautifully-written manuscripts. At this time the printing press was invented and Italian printers copying Guttenberg but not his Germanic typefaces created their own typefaces based on the humanist letter designs. It was these fixed metal typefaces which would set the letter designs as constant in shape and would be used as the basis for copy books to teach handwriting. So our modern-day handwriting is borrowed from the printed letter designs which were based on the early alphabets of the Romans, Greeks and Phoenicians and can be ultimately related back to Egyptian hieroglyphics.

\section{Quidã eius libros nõ ipfius effe fed Dionyfii \&Zophiri co}

Figure 3. Early typefaces based on Roman capitals and humanist manuscript lower case letters. Typefaces would be the basis for copy books used to teach handwriting

Source: www.wikipedia.com.

So the consonant glottal stop aleph became alpha, which via the Romans became our A. So in using the letter A today we still have the ox with us but his head is upside down and his horns are pointing downwards being the legs of the letter A. What the early Semites realised was 
that to make writing more accessible, and not just the prerogative of the educated few, was to create symbols for sounds which could be easily written - either by ink on hide or by scratching into rock. And so by a tortuous route we have inherited a relatively small number of relatively simple letter designs to describe the full range of sounds.

So this is the genius of the alphabet. It created a simple system enabling the achievement of almost universal literacy - so everyone can write and everyone can commit a crime using handwriting — thus creating the need for forensic handwriting experts. The alphabet also has a reasonable (but not huge) number of characters. The development over time of lower case, cursive writing and numerals has increased the number of possible character designs even more. This has created variety in how the alphabet can be written and allows for enough variation to give most people unique handwriting styles. The limited number of letter designs means for us that in practice a handwriting comparison can be quite difficult if there is a relatively small amount of either questioned and/or specimen material. The greater the number of letter designs which can be compared and matched the greater the confidence the handwriting expert can declare a piece of handwriting as being by the same writer. This difficulty arises out of the alphabet's origins as a simple system of designs to be easily scratched on a rock and easily read. So the ancients have given us the possibility of handwriting comparison but they have also given us the difficulty. Too few characters present in our questioned or specimen handwriting and the handwriting expert is presented with perhaps too little evidence from which to obtain an opinion of authorship.

So the presence of a limited number of relatively simple letter designs in our alphabet can be interestingly illustrated by the origins of the letter $\mathrm{C}$ and related letters. Now the Roman alphabet starts A, B, C not $\mathrm{A}, \mathrm{B}, \mathrm{G}$ as in the Greek and Hebrew alphabets. The character $\mathrm{C}$ originally started out as a $\mathrm{G}$ sound and represented a gimmel, which was a throwing stick or boomerang. Obviously there is not much to draw for a throwing stick in modern or ancient times and the hooked stick evolved into the simple half circle we know today. Of course there is variation in how we can write this half circle - fat or thin or with hooks and so on but the block capital $\mathrm{C}$ is not one of our most distinctive letter designs. 
We have the Etruscans to thank for the $\mathrm{C}$ having a 'kuh' sound in that it appears that the Etruscan language, which was a language isolate and not Indo-European, did not have a $\mathrm{G}$ sound and so they assigned the $\mathrm{C}$ letter design to the $\mathrm{K}$ sound. The Romans kept the $\mathrm{C}$ and liked it a lot, almost never using the $\mathrm{K}$ design. To the Romans it was the 'kuh' sound and not the 'ess' sound - 'Caeser' was 'Kayser' to the Romans. Linguistic changes in the Romance languages evolved the 'kuh' sound into the 'ess' sound in some languages. French particularly slurred the 'kuh' into 'ess' and English inherited this when the Norman Conquest brought the French language to England to be mixed with Old English — which is a Germanic language.

Handwriting experts look forward to seeing a $\mathrm{K}$ in a piece of handwriting as opposed to the less distinctive C. K started out as the Egyptian 'hand' symbol pronounced 'drt' and could be used for an alphabetic D symbol. The Semites liked the look of this symbol and adopted it for their alphabet, but in Semitic languages the hand took on the K sound, meaning 'palm of hand' or kaph, and was originally written as a hand and fingers pointing upwards. We still have the fingers today in the letter $\mathrm{K}$ but the orientation has changed to the right and the fingers point to the right - one up and one down. It is the formation and joining of these "fingers" in both upper case and lower case K that leads to great variation in the way we can write the letter $\mathrm{K}$ - which is of course of great use to handwriting experts. Unfortunately for British English, $\mathrm{K}$ only came into greater use later in the language's development and the $\mathrm{C}$, so widely-used in Norman French, dominates the English language in a ratio of $C: K=5: 1$. So it is the simple $C$ which outnumbers the complicated $\mathrm{K}$ in modern English - which is a disadvantage to handwriting experts. On the Celtic fringes the preponderance of a harder $\mathrm{K}$ sound has resulted in many surnames having the letter $\mathrm{K}$, particularly as a starting letter (compare English "church" with the Scottish version "kirk" - both words can be surnames) and cursive capital K's are particularly distinctive. 

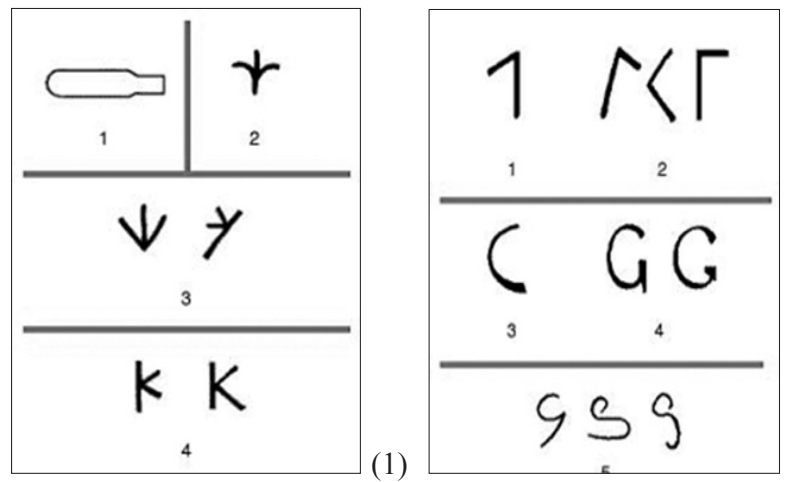

Figure 4. The development of the K (1) and G (2) through time, leading to a great variety of designs in modern usage

Source: www.wikipedia.com.

So we have the Etruscans to blame for changing gimmel into a $\mathrm{C}$ sound but the Romans really helped forensic handwriting experts by changing the $\mathrm{C}$ back into a $\mathrm{G}$. The Romans, unlike the Etruscans, did have a $\mathrm{G}$ sound and so they adapted the letter $\mathrm{C}$ to create the letter $\mathrm{G}$ and moved it to number 7 in the alphabet. The Romans added a bar to the bottom of the $\mathrm{G}$ and it is the adding of this bar to the relatively simple semi-circular $\mathrm{C}$ shape that gives us so much variety in how people write the upper case G. The Romans placed the bar upwards from the base of the letter but medieval scribes also wrote $\mathrm{G}$ with the bar as a descender, leading to even greater variety in the capital $\mathrm{G}$ shapes and also in the lower case $g$ shapes that we have inherited today. So out of the simple $\mathrm{C}$, the handwriting expert has gained a very useful letter design indeed.

Returning briefly to the Etruscans, whilst they did not have the $\mathrm{G}$ sound they evidently distinguished between different types of $\mathrm{K}$ sounds and kept $\mathrm{C}, \mathrm{K}$ and $\mathrm{Q}$ in their alphabet. These three letter designs for the $\mathrm{K}$ sound have come down to us today as a legacy of the Etruscans, and whilst handwriting experts do not have the unique symbols for unique phonemes such as $\mathrm{TH}, \mathrm{SH}, \mathrm{CH}$ or $\mathrm{NG}$ they do have some variety to work with for the $\mathrm{K}$ sound in the English language. As you can see, sound phonemes such as TH (both voiceless and voiced dental fricatives with different sounds such as the words this and thin), $\mathrm{SH}$ and $\mathrm{CH}$ use the letter $\mathrm{H}$ to represent 
these sounds in combination with other letters. Now the letter $\mathrm{H}$ started life as the Phoenician letter khet or heth with a breathy $\mathrm{KH}$ sound. Khet meant fence, and the shape was a set of horizontal lines intersecting vertical lines like a fence. The Greeks adopted the letter but gave it the $\mathrm{H}$ sound and simplified the design to one bar intersecting two verticals. This relatively simple shape and the lower case letter $\mathrm{h}$ which appeared in Christian manuscripts around AD 700 (written in one stroke and losing the right vertical) - gives us shapes which are open to a reasonable amount of variation. Unfortunately, as the Roman alphabet developed it did not generate unique characters for $\mathrm{TH}, \mathrm{CH}$ and $\mathrm{SH}$ sounds. However, the $\mathrm{TH}, \mathrm{CH}$ and $\mathrm{SH}$ letter combinations in shape, joining stroke and relative heights do give handwriting experts quite a large range of possible variants with which to base a handwriting opinion on. The TH combination in common English words like the/then/this/that are very useful for handwriting experts and the SH designs in common surnames (Shields/Sherlock/Short) when written in distinctive cursive capitals provide much distinctive variety. English originally did have a character for the TH sound - which was called a thorn (for the voiceless dental fricative as in thin) which originated from the runic alphabet. Its use was decreasing in English by the 1400s and when printing started in England typefaces were imported from continental Europe which did not use the thorn. This eventually killed off a letter design (although not until the 19th century) which would have been quite useful for handwriting experts along with other home-made letters such as the wynn and the yogh. The thorn lives on in its Y-shaped form in tourist places with affected old fashioned names such as 'Ye Olde English Tea Shoppe' and it also survives in the Icelandic alphabet.
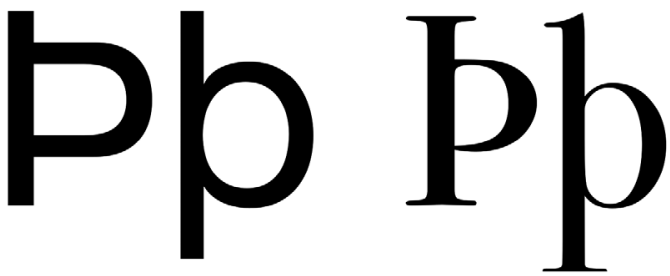

Figure 5. The obsolete letter thorn which had an alternative y shape Source: www.wikipedia.com. 
English also is very economical with its letter designs for vowels. In English, as used in the UK and Ireland, there are vast differences in regional vowel sounds, creating 20 separate vowel sounds (compared to perhaps 5 vowel sounds in Spanish). This legacy started with the Phoenicians, who did not use symbols for vowel sounds at all. When the Greeks adapted the Phoenician alphabet for their language, whilst they did change some Phoenician consonantal signs into vowels, they only did so for 5 vowel sounds. By the time the Greeks increased their number of vowel letters - by creating epsilon (literally naked e) out of eta and using the Phoenician symbol waw a second time to create $u$, which was called upsilon (literally naked $\mathrm{u}$ ) - the Greek alphabet had already been passed to the Etruscans without these symbols. As the alphabet was passed on through languages with fewer vowel sounds than English, when the Roman alphabet was adapted for English it only had 5 symbols to represent 20 vowel sounds. The 5 vowel symbols are used in semi-logical combinations to represent the 20 English vowel sounds. The process is further complicated by spellings having not changed with pronunciation over the period of the great vowel shift in the 15th-18th centuries (take the word "lead", which can be pronounced leed or led depending on the word meaning). So the way the alphabet has been inherited has meant that unfortunately for handwriting experts the alphabet is much smaller than it should be for the English language - which would need 44 separate symbols. Other languages increase the number of vowel sounds with accents but once again English does not give us this advantage of adding extra features to the alphabet - which could be of great use to the handwriting expert.

The development of the alphabet by Christian scribes in the Dark Ages and Middle Ages added much to the variability of the alphabet. Initially only capital letters were written and these were written with much the same height - and today people writing in block capital letters often keep to the same height for each letter. However, scribes began writing the first letter of manuscript pages with extra large letters - evolving into the modern habit of writing proper names and the start of sentences in larger letters. Scribes began to write quicker and more economically, reducing the loops and strokes of capital letters down to simple lower case letters often different to their capital forms. This has given us 
in the modern age a great benefit in allowing the handwriting expert to have three different types of handwriting that can be compared - block capitals and lower case (which can be joined-up cursive writing - or un-joined script writing). The disadvantage of the alphabet developing three almost mutually exclusive styles is that specimens and questioned writings need to be in the same style. This evolving of alphabets into easier to write systems is clearly a natural occurrence, as even Egyptian hieroglyphics evolved into two simpler scripts - hieratic and demotic. Lower case letters in the uncial manuscripts also began to be written with ascenders for $\mathrm{d}, \mathrm{h}, \mathrm{k}$ and $\mathrm{l}$ and descenders for $\mathrm{f}, \mathrm{g}, \mathrm{p}$ and $\mathrm{q}$ and so this added another set of variation which modern handwriting experts look for in terms of relative heights between letters and positioning of descenders with respect to the guide line.

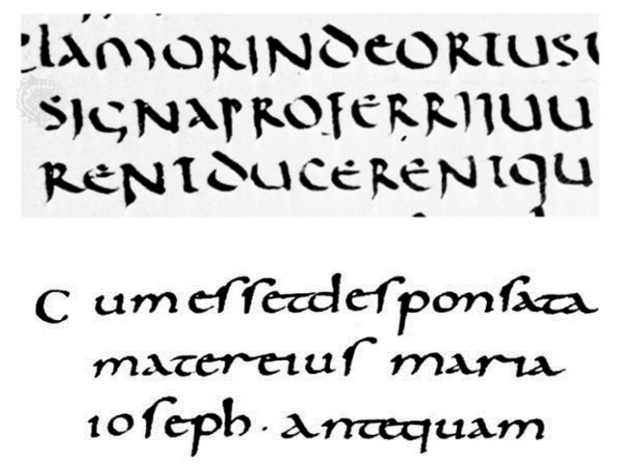

Figure 6. Uncial script (1) and Carolingian miniscule script (2)

Source: www.wikipedia.com.

What handwriting experts like least are the simplest characters such as the I and the number 1 . These can be simple lines written with very little individuality about them. The letter I evolved from the Phoenician yod which had the Y sound as a consonant and meant "arm and hand". From a simple backwards $\mathrm{Z}$ shape representing an arm and hand the straight line developed and was used by the Greeks for a vowel sound I — named iota after the yod. In writing of the Middle Ages scribes were concerned about the legibility of the single straight line, particularly in lower case 
miniscule writing styles. In fact, the small size of the I is represented in phrases such as 'not one iota' and 'jot' down a brief note - from the Biblical quotation 'jot and tittle' itself from the Hebrew letter word yod. To increase the presence of the letter I in written manuscripts, scribes started adding a diacritic similar to an acute. This developed into the modern I dot in lower case letters with its increased propensity for variation in terms of dot shape and positioning. This dot is also present in the letter $\mathrm{J}$ as the letter $\mathrm{J}$ developed as an extension of the letter I. Lower case $\mathrm{J}$ however is relatively rare in English and the dotted $\mathrm{j}$ is not as interesting a feature as the dotted i. Whilst the I dot is very useful to British and Irish handwriting experts, the lack of other accents in British English, except in a few borrowed words such as café, is another limitation to their expertise.

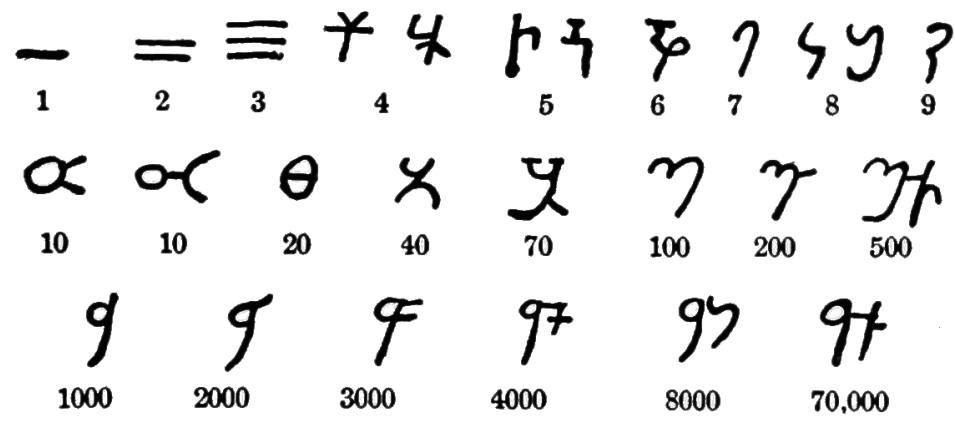

Figure 7. Early number designs used in India which would develop into the numbers we use today

Source: www.wikipedia.com.

The other character written with one stroke is the numeral 1. Numbers were originally counted on the hands and the number one will originally have been just a representation of a finger. Likewise the Roman numeral $\mathrm{V}$ is believed to have originated from the shape of the five fingers held out with the thumb extended out from the other four fingers. Our current set of numerals originated in India and came to us via the Arabs and are known as Hindu-Arabic numerals. The numbers 1, 2 and 3 all started out as lines representing fingers but horizontally as opposed to vertically. In 
fact, the 2 and 3 still look like two fingers and three fingers held horizontally today but joined by curves. The simple curved structures of the 2 and 3 give us some variability in how they are written between writers but are also prone to great variability within the same writer - making handwriting opinions on the numbers 2 and 3 quite difficult. Harder still is handwriting comparison using the number 1 , which is almost always written as a straight vertical line in Britain and Ireland - without any distinctive features. Continental versions of the numeral 1 have a head to them and this feature sparks great interest when seen in a piece of handwriting by British and Irish handwriting experts. Of course the confusion of the numeral 1 with a head and the numeral 7 with an extended head has led to the practice of writing the number 7 with a bar through the middle. This continental European practice has been embraced by the British and Irish, but not universally, and so handwriting can still be distinguished between people who write the 7 with the middle bar and people who do not. However, handwriting experts must also be aware that a few people use both ways of writing the number 7 .

\section{Conclusion}

Whilst I have used only a few examples, I hope this exercise has shown how the development of the alphabet over the millennia still has implications for handwriting experts today. The development of each letter design and other graphic features has resulted in features which can both aid handwriting comparison and limit it.

\section{References}

Clodd E. (1900), The Story of the Alphabet, Newnes, London.

Harrison W.R. (1966), Suspect Documents, Sweet \& Maxwell, London.

Sacks D. (2003), The Alphabet, Hutchinson, London.

\section{Summary}

The development of the alphabet from about $2000 \mathrm{BC}$ to the modern age has interesting implications in the work of forensic handwriting analysts. This overview provides 
background knowledge for the forensic handwriting expert as to why some letter designs are more useful than others when it comes to handwriting comparisons. Numerals are also considered. The overview is directed for the alphabet as used in the British and Irish spheres, but can be extrapolated to other localities.

Keywords: handwriting examination, historical circumstances, graphic features, development of handwriting, significant features. 